\title{
The application of penetrating compounds for repairing concrete, reinforced concrete and stone structures
}

\author{
Medeia Saliia ${ }^{1, *}$, Alexander Rachkovskyi ${ }^{2}$, Allayar Gasanov ${ }^{2}$, Ruslan Shemet ${ }^{1}$, and \\ Vladimir Zemlyakov ${ }^{1}$ \\ ${ }^{1}$ Kharkiv National University of Civil Engineering and Architecture, Department of Reinforced \\ Concrete and Stone Structures, 61002 Sumska st, 40, Kharkiv, Ukraine \\ ${ }^{2}$ Kharkiv National University of Civil Engineering and Architecture, Department of Building \\ Materials and Products, 61002 Sumska st, 40, Kharkiv, Ukraine
}

\begin{abstract}
Repair and protection of structural elements remain a relevant issue throughout the whole period of building operation and maintenance. Housing and public facilities regularly require rehabilitation and major repair. One of the main reasons behind a shorter lifespan of structural elements and units in a building is the impact on them of aggressive liquid and gaseous environments. The application of newly-developed cementitious products with penetrating properties is suggested in order to maintain and restore the protective properties of the concrete and reinforced concrete structures.
\end{abstract}

Buildings and structures in operation are subject to regular surveys aimed at assessing physical conditions of their structural elements. On the basis of visual observation and instrumental measurements a technical report is prepared which suggests further rehabilitation, repair and restoration measures to ensure safety, durability, overall performance and longevity of structural elements.

Deterioration and distress of concrete, reinforced concrete and stone structures are mainly caused by the integrated effect of various types of loads and exposure to aggressive environments. The most common are nonuniform shrinkage, temperature action, weathering effect and exposure to chemicals. The porous structure of building elements is vulnerable to external forces such as carbon dioxide, oxygen, and moisture, which trigger chemical reactions resulting in cracking and disintegration.

Over time, in the process of building operation, the $\mathrm{pH}$ value of the porous concrete structure in contact areas gradually approaches the point when it becomes aggressive for steel reinforcement. The porous structure of concrete itself results in electrochemical corrosion caused by exposure to vagrant currents. These adverse processes lead to corrosion of steel reinforcement with the subsequent deterioration of concrete and premature wear of their structural elements [1].

The surfaces of concrete and reinforced concrete structures can be effectively protected by means of applying special coatings. The most important property of protective

\footnotetext{
*Corresponding author: medeasalia@gmail.com
} 
penetrating products is their ability to regenerate old concrete, which makes them useful for renovation and waterproofing works as long as there is no more need for prior cleaning and drying of concrete and stone backings.

The action principle behind penetrating waterproofing products is the following. Chemically active ingredients penetrate into the pores and capillary tracks of the concrete where they react with free lime and sediment on the surface of the pores. The pores (or micro cracks) are filled out reducing permeability and helping to waterproof the concrete. In addition, there is also a strong, 2-3-mm-thick coating of plaster on top of the concrete, which protects the concrete and prevents active ingredients from being washed away under direct water flow. Should the structure come in contact with water molecules, the reaction resumes and the sealing process advances deeper into the concrete. The same process lies behind the "self-healing" of micro cracks. Manufactured in the form of dry mix with penetrating properties, the products based on mineral bonding agents are used in foundations and backings with developed capillary porosity (concrete, reinforced concrete, brickwork, etc.) These are the following protective products: Penetron, Xypex, Kalmatron, Kalmaflex, Aquatron, Hydrotex, Viatron. Coatings up to $5 \mathrm{~mm}$ thick effectively protect concrete structures from external aggressive forces [2,3].

In order to ensure durability, strength and longevity of building structures, their surfaces require protection from external effects. Compounds manufactured in the form of dry mixes have received wide application.

Cementitious compounds with penetrating properties that are used to protect concrete surfaces have the following effect:

- restore deteriorated surfaces of concrete and masonry structures;

- improve the overall performance of the material, reduce permeability, protect from freeze-thaw cycles;

- enhance resistance to cracking under dynamic and static loads;

- protect structures and steel reinforcement from corrosion;

- protect structures in aggressive environments;

- ensure waterproofing [4].

The overall performance and longevity of restored structures is determined by the mineral composition of dry building mixes with cement binders, as well as by their proportions, micro- and macrostructure.

Regression analysis [5] was applied in the course of the experiment which helped to establish the composition of dry waterproofing mix (Table 1).

Table 1. Dry waterproofing mix

\begin{tabular}{|l|c|}
\hline \multicolumn{1}{|c|}{ Component } & Content, \% \\
\hline Portland cement & 30 \\
Quartz sand & 65 \\
Carbonate additive & 3.8 \\
Chopped glass fiber & 0.1 \\
Composite chemical additive & 1.1 \\
\hline
\end{tabular}

The method of mathematical modeling helped to establish the optimal content of finegrained additives in a dry building mix with cement binders, the resulting quantities being $0.356 \%$ of glass fiber and $13 \%$ of carbonate aggregate. The experiment showed that the content of fiber glass additive ranging within $0.02 \%-0.5 \%$ of the mass of the cement does not affect the strength of the samples.

The designed compositions include ingredients made from available local materials. The physical and mechanical properties, as well as the overall performance parameters of the composition designed in the course of laboratory experiments are shown in Table 2. 
Table 2. Physical and mechanical properties and performance parameters of the samples after 28 days of standard curing.

\begin{tabular}{|l|c|c|}
\hline \multicolumn{1}{|c|}{ Property } & Unit of measure & Actual value \\
\hline Compressive strength & $\mathrm{MPa}$ & 46.5 \\
\hline Rupture strength & $\mathrm{MPa}$ & 13.1 \\
\hline Resistance to direct pull from concrete backing & $\mathrm{MPa}$ & 2.6 \\
\hline Water tightness & $\mathrm{atm}$. & $W 12$ \\
\hline Freeze-thaw resistance & cycles & more than $F 200$ \\
\hline Resistance to cracking (observed visually) & - & absence of cracks \\
\hline Water adsorption by mass & $\%$ & 0.56 \\
\hline
\end{tabular}

These compounds [6] are widely used to protect concrete surfaces and restore performance properties of various buildings and structures, water tanks, underground parking, sewage systems, water treatment facilities, foundations, as well as hydraulic structures such as piers, dams, docks, etc.

Upon the completion of the experimental part of the research, a trial batch of the newlydevised dry building mix was produced and used for renovation and construction works in a number of facilities in Kharkiv (Fig. 1-3).

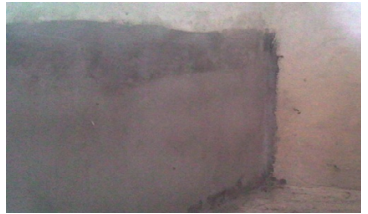

a

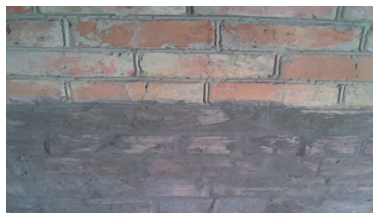

b

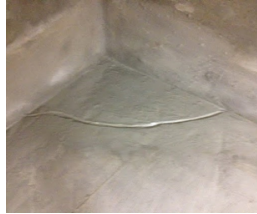

C

Fig. 1. Examples of using dry building mix for waterproofing coating: a - plastered surface treatment; b - brickwork treatment; c - waterproofing of floor surfaces.

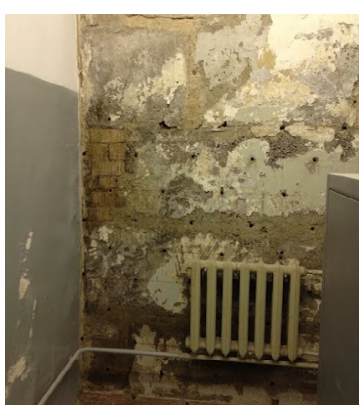

Fig. 2. Protective wall coating in a basement.

Cementitious capillary waterproofing compounds prove to be the most effective protective coatings for repairing concrete, reinforced concrete and stone structures. These protecting and repairing products can be applied both internally and externally in the form of plaster mix and external protective coatings. The research and practical application of dry mixes confirm all the properties and performance parameters of the devised compounds. 

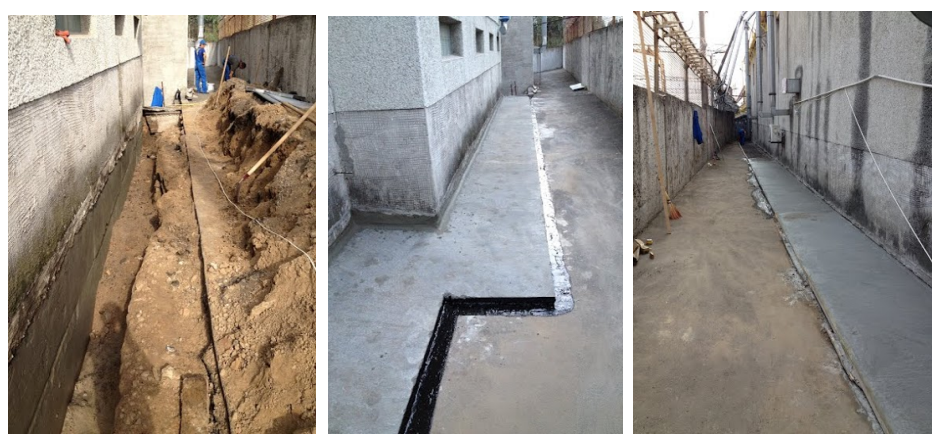

Fig. 3. Waterproofing of foundations and blind areas.

\section{References}

1. L. Bertolini, J. Wiley \& Sons. Corrosion of steel in concrete: prevention, diagnosis, repair, 434 (2013)

2. T.A. Kostyuk. Directional formation of the structure of cement compositions for waterproofing. Dr. sci. diss., 289 (2015)

3. A.I. Voytov, V.L. Kozachuk, V.V. Lakin, A.A. Shkuratovskiy. Modern waterproofing materials, 204 (2002)

4. T. Andreychuk. Survey of capital construction, 2, 16-20 (2004)

5. Saliia M.G. Waterproofing coating on a cement base with increased crack resistance. PhD sci. diss., 153 (2012)

6. T.A. Kostyuk, A.G. Vandolovskiy, M.G. Saliia, D.A. Bondarenko. Dry mixes for repairs. Patent of Ukraine 57543 UA MPK S04V 24/00, (2011) 